\title{
Ángel Leopoldo López Escobar (1940-2013)
}

\author{
Hugo Moreno Roa ${ }^{1}$
}

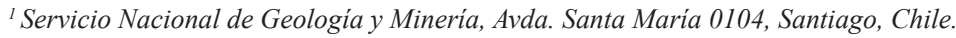

hugo.moreno@sernageomin.cl

El 29 de junio de 2013, después de una prolongada enfermedad, nos dejó para siempre nuestro querido colega y amigo Leopoldo López, el 'Leo' o 'tío Leo' como le decíamos cariñosamente sus alumnos y compañeros de trabajo.

En su vida profesional, destacó como investigador activo y académico entusiasta en la disciplina que le apasionaba: la geoquímica y petrogénesis de rocas volcánicas, línea en la que llegó a ser un referente internacional.

Leo nació el 5 de agosto de 1940 en Santiago y vivió su infancia en la hermosa ciudad de Los Andes, cuyo entorno motivó una temprana vocación científica. Recibió una educación estricta y religiosa, que en la secundaria completó en Los Hermanos Maristas para ingresar en 1957 a la carrera de Biología y Química en la Pontificia Universidad Católica de Santiago. El piano y la música clásica lo acompañaron toda su vida. Licenciado como profesor de Biología y Química en febrero de 1963, su vida académica comenzó a desarrollarse en la Universidad Austral de Valdivia como profesor de Química General y Fisicoquímica, donde estuvo hasta 1968. Sus virtudes como investigador y profesor lo llevaron al Massachusetts Institute of Technology (MIT), lugar donde obtuvo el grado de Magíster en Ciencias Químicas, Magíster en Ciencias de la Tierra y Planetarias y el grado de Doctor en Geoquímica con la guía del profesor Fred Frey.

En 1974 regresa a Chile y se integra al grupo académico del Departamento de Geología de la Universidad de Chile con la misión de desarrollar una nueva línea de investigación centrada en la petrogénesis de las rocas volcánicas andinas mediante el análisis de las tierras raras. Más tarde, en 1976, recibe el grado de Doctor en Ciencias Geológicas en la misma universidad. Durante esa etapa, su pasión por la docencia se volcó en los cursos de Fisicoquímica, Termodinámica de la Tierra y Geoquímica General, además de otros en los que colaboraba

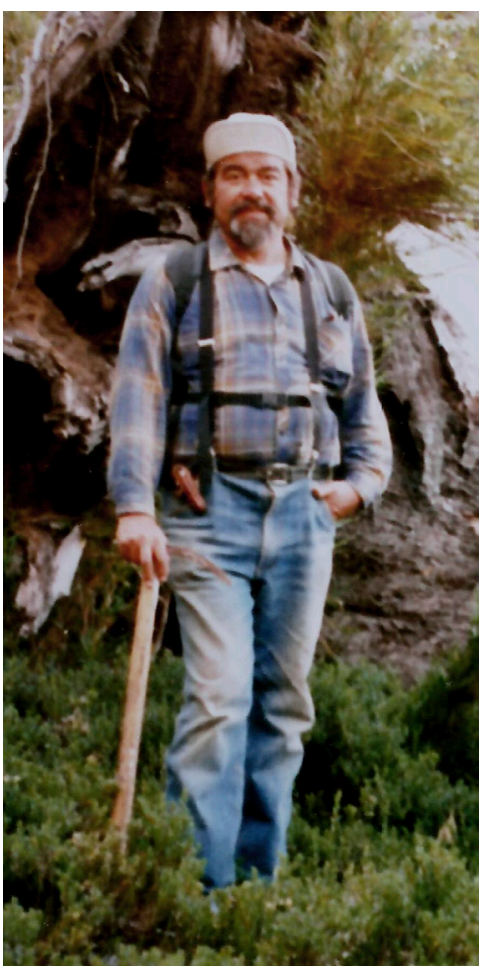

regularmente, por ejemplo Petrología Volcánica y Volcanología. Su actividad docente se proyectó también internacionalmente, dictando cursos en Francia, Japón, Reino Unido, Estados Unidos y gran parte de Latinoamérica. Asimismo, fue un mentor dedicado, dirigiendo alrededor 15 memorias y tesis en diferentes universidades e integrando un sinnúmero de comisiones.

Leo mantuvo una activa colaboración nacional e internacional, participó de proyectos financiados por la NSF y Conicyt, entre los que destacan varios proyectos Fondecyt desde el inicio de este programa en 1982. Como resultado, es autor de más de 200 publicaciones científicas entre las cuales se cuentan algunas importantes en Andean Geology. 
No puedo dejar de mencionar su afable carisma y gran compañerismo durante las investigaciones que desarrollamos en los volcanes de los Andes del Sur por más de 35 años. Entre las anécdotas interesantes, cabe recordar nuestra injustificada sorpresa en el muestreo de la fumarola del volcán Mirador en 1979, mediante un rudimentario sistema que consistía en un matraz, una manguera, un tubo de vidrio y una 'pera' para bombear el gas y que arrojó una elevada concentración de $\mathrm{HCl}$. En efecto, A. Pissis había hecho similar descubrimiento en el volcán Antuco en 1861. Por otra parte, el entusiasmo y pasión de Leo motivaban fructíferas discusiones con los alumnos en lugares tan impresionantes como el borde de la caldera del volcán Villarrica o la cima del volcán Quetrupillán.

Santiago de Chile, Septiembre del 2013
En 1996 asumió como director del instituto GEA de la Universidad de Concepción y con ello se abrió a otras líneas de investigación como la metalogénesis de sistemas magmáticos, en la que mantuvo hasta su retiro una activa colaboración. Asimismo, sus actividades docentes continuaron con igual entusiasmo hasta 2010 en los cursos de Volcanología y Volcanología Aplicada.

Leopoldo fue muy querido por alumnos, profesores y colegas por estar siempre dispuesto a compartir su conocimiento. Fue un hombre brillante, generoso y amante de su familia. El 29 de junio comenzó la salida a terreno que seguramente más preparó durante los últimos años, puesto que los volcanes más colosales y maravillosos se encuentran en el cielo. Querido Leo, ahora conseguiste la explicación a todo. 